\title{
Cisplatin improves antitumor activity of weekly nab-paclitaxel in patients with metastatic breast cancer
}

This article was published in the following Dove Press journal:

International Journal of Nanomedicine

19 March 2014

Number of times this article has been viewed

Si Sun'
Lichen Tang'
Jian Zhang'
Fangfang Lv'
Zhonghua Wang'
Leiping Wang'
Qunling Zhang'
Chunlei Zheng'
Lixin Qiu'
Zhen Jia'
Yunhua Lu'
Guangyu Liu²
Zhimin Shao
Biyun Wang'
Xichun Hu'

'Department of Medical Oncology, Fudan University Shanghai Cancer Center, Department of Oncology, Shanghai Medical College, Fudan University, Shanghai, People's Republic of China, ${ }^{2}$ Department of Breast Surgery, Fudan University Shanghai Cancer Center, Department of Oncology, Shanghai Medical College, Fudan University, Shanghai, People's Republic of China
Correspondence: Biyun Wang; Xichun Hu Department of Medical Oncology, Fudan University Shanghai Cancer Center, 270 Dong An Road, 200032, Shanghai, People's Republic of China

Tel +86 2l 641755905009 (Biyun Wang) +862I 641755905006 (Xichun Hu) Fax +862164430160

Email wangbiyun@msn.com; huxicun@gmail.com
Abstract: Although nanoparticle albumin-bound paclitaxel (nab-paclitaxel) is approved to be given every 3 weeks, weekly use of this drug is becoming a new standard of care in patients with metastatic breast cancer (MBC). This prospective Phase II study was conducted to improve the efficacy of weekly nab-paclitaxel with cisplatin in MBC patients. Seventy-three women with recurrent or $\mathrm{MBC}$ were eligible for participation. Nab-paclitaxel was administered weekly at a dose of $125 \mathrm{mg} / \mathrm{m}^{2}$ on day 1 , day 8 , and day 15 , followed by cisplatin $75 \mathrm{mg} / \mathrm{m}^{2}$ on day 1 , repeated every 28 days with a maximum of 6 cycles. The primary objective was investigatorassessed overall response rate (ORR). A high ORR of $67.1 \%$ was obtained, with rates of $80.6 \%$ for the first-line patients and $80 \%$ for patients not pretreated with taxanes. Among those who had objective responses, a large percentage of patients $(83.7 \%)$ showed quickly remarkable tumor shrinkage during the first two cycles. The median progression-free and overall survival times were 9.8 and 26.9 months, respectively. For the patients receiving first-, second-, and third-line therapy or beyond, median progression-free survival was 11.7, 7.7, and 7.6 months, respectively $(P=0.005)$. Molecular subtype was not significantly associated with ORR or disease progression. Grade 4 neutropenia occurred in 46 patients $(63.0 \%)$, with febrile neutropenia found in 9 patients $(12.3 \%)$. Grade 3 peripheral neuropathy was an accumulated dose-limiting toxicity occurring in 19 patients $(26.0 \%)$. Efficacy of weekly nab-paclitaxel can be improved by adding cisplatin. The doublet is highly effective, with quick response, manageable toxicity, and possible equivalence across molecular subtypes in MBC patients.

Keywords: metastatic breast cancer, nanoparticle albumin-bound paclitaxel, cisplatin, taxanepretreated

\section{Introduction}

Breast cancer is the most common cancer and the most common cause of cancer-related death in women. ${ }^{1}$ Despite earlier diagnosis and improvement in adjuvant therapies, approximately $20 \%-40 \%$ of the patients initially diagnosed with earlier stages of breast cancer eventually develop recurrent or metastatic disease..$^{2-4}$ Despite various treatments used in patients with metastatic breast cancer (MBC), the best 5-year relative overall survival (OS) rate is only $20 \%,{ }^{5}$ and the median OS time is 2 to 3 years. ${ }^{6}$ Therefore, treatments that provide clinical benefit among these patients will continue to be sought.

Taxanes, such as solvent-based paclitaxel (sb-paclitaxel) and docetaxel, are considered one standard of care for patients with breast cancer. However, these drugs are highly hydrophobic and need synthetic solvents to enable parenteral administration. Paclitaxel contains a combination of polyethylated castor oil (Cremophor EL; BASF, Ludwigshafen, Germany) and ethanol as the vehicle; polysorbate 80 and an ethanol 
diluent are the vehicles for docetaxel. These solvents directly contribute to severe hypersensitivity reactions and myelosuppression observed in patients treated with paclitaxel or docetaxel, even with corticosteroid premedication.

Nab-paclitaxel (Abraxane ${ }^{\circledR}$ for injectable suspension; Abraxis BioScience, Los Angeles, CA, USA), an albuminbound $130 \mathrm{~nm}$ particle form of paclitaxel, was developed to avoid toxicities associated with the Cremophor vehicle in sbpaclitaxel. ${ }^{7-10}$ Preclinical data in animals have demonstrated increased antitumor activity of nab-paclitaxel compared with equitoxic doses of sb-paclitaxel. ${ }^{11}$ These findings were confirmed clinically, and nab-paclitaxel consistently demonstrates superior efficacy compared with sb-paclitaxel. In a phase III trial, nab-paclitaxel showed a significantly higher overall response rate (ORR), a longer time to progression (TTP), and greater OS in patients treated with second-line or greater therapy compared with patients who received sb-paclitaxel. ${ }^{8}$ Furthermore, weekly nab-paclitaxel can be safely administered at doses exceeding those typically used for sb-paclitaxel, ${ }^{12}$ is effective in taxane resistant patients, ${ }^{13}$ and as a single drug is more effective than docetaxel, which was previously considered the most potent drug for MBC. ${ }^{14}$ Therefore, weekly nabpaclitaxel is becoming a standard of care for MBC patients.

To further improve the efficacy of weekly nab-paclitaxel in MBC patients, several studies tested combinations by adding other chemotherapeutic agents or biologicals. In the current Phase II study, conducted in the Department of Medical Oncology, Fudan University Shanghai Cancer Center, People's Republic of China, we assessed the efficacy and safety of combination of nab-paclitaxel and cisplatin in patients with MBC.

\section{Patients and methods}

\section{Patients}

Women older than 18 years with pathologically confirmed unresectable stage IV breast cancer, measurable disease according to the Response Evaluation Criteria in Solid Tumors (RECIST) $1.1,{ }^{15}$ as well as an Eastern Cooperative Oncology Group performance status of $0-2,{ }^{16}$ were eligible for inclusion. Therapy with a taxane as part of adjuvant or neoadjuvant therapy was allowed but should have been completed at least 12 months before study entry. Prior taxanes in the metastatic setting were also permitted if they were completed at least 3 months before study enrolment.

Patients were excluded if they had clinical evidence of brain metastasis or clinically serious concurrent diseases, preexisting peripheral neuropathy higher than grade 1, concurrent hormonal therapy or immunotherapy, or other malignancy within the last 5 years that could affect the diagnosis or assessment of breast cancer.

The trial was approved by the Ethics Committee of Fudan University Shanghai Cancer Center and carried out in accordance with the principles of Good Clinical Practice and the Declaration of Helsinki. All patients provided written informed consent before any study-related procedure (ClinicalTrials.gov identifier: NCT01149798). ${ }^{17}$

\section{Treatment}

Eligible patients received treatment every 4 weeks with a combination of nab-paclitaxel and cisplatin. Nab-paclitaxel was administered at a dose of $125 \mathrm{mg} / \mathrm{m}^{2}$, over 30 minutes, on days 1,8 , and 15 , without corticosteroid or antihistamine premedication or special infusion sets. Cisplatin was given at a dose of $75 \mathrm{mg} / \mathrm{m}^{2}$ on day 1 with hydration for 3 continuous days. The treatment continued until disease progression, intolerable toxicities, or a maximum of six cycles. If grade 4 neutropenia occurred over the course of more than 7 days or febrile neutropenia occurred, the patients continued the next cycle at a reduced dose after the hematologic toxicity recovered to grade 1 or less. If grade 3/4 nonhematologic toxicities except nausea/vomiting occurred, the patients withheld the treatment until the toxicity recovered to grade 2 or lower and then continued at the lowered dose. Treatment could be delayed up to 14 days to allow sufficient time for recovery from hematologic or nonhematologic toxicities. Treatment was permanently discontinued if dose modification of more than double was required, with a $20 \%-25 \%$ reduction each time.

\section{Assessments}

Pretreatment evaluation included a complete medical history and physical examination, hematological and biochemical profiles, carcinoembryonic antigen and cancer antigen 15-3, electrocardiography, bone scan (if clinically indicated), computerized tomography of the chest, and magnetic resonance imaging of the abdomen. During treatment, complete blood counts were performed weekly, or every 2 days in the case of grade 3/4 neutropenia or thrombocytopenia, until hematologic recovery.

The primary endpoint of this study was investigatorassessed ORR, and the secondary endpoints were progressionfree survival (PFS), OS, and safety. Efficacy was evaluated in patients who received at least 2 cycles of chemotherapy. All patients were assessed for tumor response every 8 weeks by clinical examination and radiographic assessments (computed tomography or magnetic resonance imaging). 
Disease status was assessed by investigators according to RECIST 1.1. All radiographic images were copied and provided to the independent radiologists and reviewed in a blinded fashion following the RECIST 1.1 criteria. Complete response (CR) was defined as the disappearance of all known lesions and the normalization of tumor marker level for at least 4 weeks. Partial response (PR) was defined as a reduction of the sum of all measurable lesions by at least $30 \%$ for at least 4 weeks. Progressive disease was defined as an increase of the sum of all measurable lesions by greater than $20 \%$ or the appearance of a new lesion, and stable disease was defined as neither CR and PR nor progressive disease. ORR was defined as the sum of CR and PR rates. In patients with tumor response or stable disease, treatment was planned to be continued for up to 6 cycles; thereafter, maintenance therapy was not recommended but could be started at the clinician's decision. After completion of the treatment period, the patients were followed-up every 3 months.

All toxicities were graded according to the National Cancer Institute Common Terminology Criteria for Adverse Events (AEs) 4.0. ${ }^{18}$

\section{Statistical analysis}

Sample size was calculated on the basis of Simon's two-stage Phase II clinical trial design. ${ }^{19}$ The ORR of combination was hypothesized as $60 \%$ with the addition of cisplatin in the whole population compared with $40 \%$ for nab-paclitaxel monotherapy, as reported in published studies. ${ }^{13,14}$ The design had $90 \%$ power with a type 1 error of $\alpha=0.05$. If 11 of the first 25 patients enrolled achieved CR or PR, the study moved to the second stage, and if there were 32 patients responding of 66 total patients assessed by investigators and the results were confirmed by an independent review, the study was positive to prove the hypothesis. The sample size was calculated as 72 , including a $10 \%$ dropout rate.

All statistical analyses were carried out on SPSS 20.0 software (IBM Corporation, Armonk, NY, USA). PFS was calculated for all intention-to-treat patients as the time from inclusion to disease progression or death from any cause. OS was calculated for all patients from the date of inclusion until death. The PFS and OS were computed using the Kaplan-Meier method. The statistical difference was considered significant if the $P$-value was less than 0.05 .

\section{Results \\ Patients}

A total of 73 patients were enrolled into this study starting in June 2010, and all received at least a single injection of the study drug and were evaluated for efficacy and safety. The patient characteristics are listed in Table 1. The median age of patients was 49 years (range, 33-65 years). The majority of patients $(93.2 \%)$ relapsed after primary radical surgery for breast cancer; only 5 patients $(6.8 \%)$ initially presented with de novo stage IV diseases. Thirty-four patients (46.6\%) had involvement of more than three metastatic sites, and 59 patients $(80.8 \%)$ had visceral diseases. Nearly half of the patients $(49.3 \%)$ were chemonaïve for metastatic diseases, whereas $28(38.4 \%)$ and $9(12.4 \%)$ patients received chemotherapy as second-line and third-line therapy or beyond, respectively.

Table I Patient characteristics $(n=73)$

\begin{tabular}{|c|c|c|}
\hline Characteristics & Number & $\%$ \\
\hline \multicolumn{3}{|l|}{ Age (years) } \\
\hline Median & 49 & \\
\hline Range & $33-65$ & \\
\hline \multicolumn{3}{|l|}{ Amenorrhea } \\
\hline Premenopausal & 29 & 39.7 \\
\hline Postmenopausal & 44 & 60.3 \\
\hline \multicolumn{3}{|l|}{ Radical mastectomy } \\
\hline No & 5 & 6.8 \\
\hline Yes & 68 & 93.2 \\
\hline \multicolumn{3}{|l|}{ Time to first relapse (years) } \\
\hline Median & 2.55 & \\
\hline Range & $0.4-17$ & \\
\hline \multicolumn{3}{|l|}{ Number of metastatic sites } \\
\hline One & 15 & 20.5 \\
\hline Two & 24 & 32.9 \\
\hline Three or more & 34 & 46.6 \\
\hline \multicolumn{3}{|l|}{ Metastatic sites } \\
\hline Visceral & 59 & 80.8 \\
\hline Lung & 40 & 54.8 \\
\hline Liver & 27 & 37.0 \\
\hline Nonvisceral & 14 & 19.2 \\
\hline Bone & 23 & 31.5 \\
\hline \multicolumn{3}{|l|}{ Subgroups } \\
\hline Luminal type & 46 & 63.0 \\
\hline $\begin{array}{l}\text { Human epidermal growth factor } \\
\text { receptor } 2 \text {-positive }\end{array}$ & 8 & 11.0 \\
\hline Triple-negative & 16 & 21.9 \\
\hline Unknown & 3 & 4.1 \\
\hline \multicolumn{3}{|l|}{ Lines of chemotherapy } \\
\hline First-line & 36 & 49.3 \\
\hline Second-line & 28 & 38.4 \\
\hline Third- or more line & 9 & 12.4 \\
\hline \multicolumn{3}{|l|}{ Prior chemotherapy } \\
\hline \multicolumn{3}{|l|}{ Adjuvant/neoadjuvant $(n=68)$} \\
\hline Anthracycline-containing & 53 & 72.6 \\
\hline Taxane-containing & 34 & 50.0 \\
\hline Both & 27 & 39.7 \\
\hline \multicolumn{3}{|l|}{ Chemotherapy for MBC $(n=37)$} \\
\hline Anthracycline-containing & 6 & 16.2 \\
\hline Taxane-containing & 12 & 32.4 \\
\hline Both & 3 & 8.1 \\
\hline
\end{tabular}




\section{Efficacy}

All patients were assessed by both investigators and independent radiologists. The efficacy assessment by investigators is listed in Table 2. The ORR for the whole population was $67.1 \%$ by investigator assessment, with 7 (9.6\%) CRs and 42 (57.5\%) PRs. Among those who had objective responses, 41 patients (83.7\%) got objective responses after the initial two cycles, whereas five and three patients achieved PR or CR after four and six cycles, respectively. For the 36 patients in the first-line setting, 6 patients (16.7\%) achieved CR, and $23(63.9 \%)$ achieved $\mathrm{PR}$, giving a response rate of $80.6 \%$. The response rates for the patients receiving second-line treatment or third-line treatment or beyond were $57.1 \%$ and $44.4 \%$, respectively. A higher response rate $(80 \%)$ was also observed in patients who had not received taxanes, either in the neoadjuvant/adjuvant setting or metastatic setting, compared with $58.1 \%$ in those pretreated with taxanes $(P=0.076)$. Objective response was not associated with visceral involvement, liver metastasis, lung metastasis, the number of metastatic sites, and so on (data not shown). The comparison between investigator and independent radiology assessment is listed in Table 3 . The efficacy results were quite similar, with no significant difference between investigator and independent radiology reviews.

\section{PFS and OS}

After the median follow-up of 26.3 months, 37 patients (50.7\%) died; the median OS (mOS) was 26.9 months (Figure 1A). The patients not pretreated with taxanes showed longer median OS (not reached) compared with those pretreated with taxanes (16.7 months; $P<0.001$; Figure 1B). Sixty-six patients $(90.4 \%)$ had disease progression or death, among whom one died of non-breast-cancer related causes. The median
PFS (mPFS) was 9.8 months (95\% confidence interval [CI], 8.1-11.6 months) by investigator assessment and 9.3 months (95\% CI, 7.6-11.0 months) by independent assessment (Figure 2A and B). By both investigator and independent assessment, median PFS decreased significantly with the successive chemotherapy regimen. For the patients receiving first-, second-, and third-line therapy or beyond, median PFS was $11.7,7.7$, and 7.6 months, respectively $(P=0.005)$ by investigator assessment and, correspondingly, 11.7, 6.6, and 7.6 months, respectively, by independent review $(P=0.006$; Figure $2 \mathrm{C}$ and $\mathrm{D})$. The longer PFS was also seen in patients not treated with taxanes previously. Median PFS for patients with and without prior taxanes was 8.5 and 11.2 months, respectively $(P=0.009)$, by investigator assessment, and correspondingly, 7.6 and 11.2 months, respectively, by independent review $(P=0.009$; Figure $2 \mathrm{E}$ and $\mathrm{F})$.

\section{Molecular subtype analysis}

Molecular subtyping in our data was based on an analysis of the primary tumor, not the recurrent or metastatic lesion. Seventy patients (95.9\%) with the molecular subtype information available were divided into three subgroups: luminal type ( $\mathrm{n}=46$, 63.0\%), human epidermal growth factor receptor 2 (HER2)positive type $(\mathrm{n}=8,11.0 \%)$, and triple-negative type $(\mathrm{n}=16$, $21.9 \%$ ). The results of immunohistochemistry (IHC) tests were not available in the other three patients (4.1\%). Subgroup analysis showed that objective response among the three subtypes was not statistically significant by investigator assessment $(P=0.912)$, as well as independent radiology assessment ( $P=0.070$ ). The PFS was not significant among the three subtype groups ( $P=0.323$ by investigator assessment; $P=0.301$ by independent radiology assessment).

Table 2 Treatment efficacy assessed by investigators

\begin{tabular}{|c|c|c|c|c|c|c|c|}
\hline Variable & $\mathbf{N}$ & $\begin{array}{l}\text { Overall } \\
\text { response rate }\end{array}$ & $P$-value & $\begin{array}{l}\text { Median progression-free } \\
\text { survival (months) } \\
{[95 \% \text { confidence interval] }}\end{array}$ & $P$-value & $\begin{array}{l}\text { Median overall } \\
\text { survival (months) } \\
{[95 \% \text { confidence interval] }}\end{array}$ & $P$-value \\
\hline Whole group & 73 & $67.1 \%$ & & $9.8[8.1-11.6]$ & & $26.9[22.4-31.4]$ & \\
\hline Lines of treatment & & & 0.043 & & 0.005 & & 0.178 \\
\hline First-line & 36 & $80.6 \%$ & & $11.7[10.4-13]$ & & Not reached & \\
\hline Second-line & 28 & $57.1 \%$ & & $7.7[4.1-11.2]$ & & $23.4[13.7-33.1]$ & \\
\hline Third- or more line & 9 & $44.4 \%$ & & $7.6[4.1-11.0]$ & & 25.0 & \\
\hline Molecular subtypes & & & 0.912 & & 0.323 & & 0.711 \\
\hline Luminal & 46 & $67.4 \%$ & & $8.9[7.4-10.4]$ & & $26.0[21.5-30.5]$ & \\
\hline Her-2-positive & 8 & $75.0 \%$ & & $8.2[0-30.1]$ & & Not reached & \\
\hline Triple-negative & 16 & $68.8 \%$ & & $10.3[9.9-10.7]$ & & 22.5 & \\
\hline Prior taxane & & & 0.076 & & 0.009 & & 0.000 \\
\hline Yes & 43 & $58.1 \%$ & & $8.5[6.0-11.0]$ & & $16.7[11.5-22.0]$ & \\
\hline No & 30 & $80.0 \%$ & & II.2[9.4-13.0] & & Not reached & \\
\hline
\end{tabular}


Table 3 Comparison between investigator and independent radiology review

\begin{tabular}{lll}
\hline Variable & $\begin{array}{l}\text { Investigator } \\
\text { review }\end{array}$ & $\begin{array}{l}\text { Independent } \\
\text { radiology review }\end{array}$ \\
\hline Overall response rate & $67.1 \%$ & $68.5 \%$ \\
Complete response & $9.6 \%$ & $6.8 \%$ \\
Partial response & $57.5 \%$ & $61.6 \%$ \\
Stable disease & $16.4 \%$ & $26.0 \%$ \\
Progressive disease & $16.4 \%$ & $5.5 \%$ \\
Overall response rate by lines of chemotherapy & \\
First-line & $80.6 \%$ & $77.8 \%$ \\
Second-line & $57.1 \%$ & $57.1 \%$ \\
$\quad$ Third- or more lines & $44.4 \%$ & $66.7 \%$ \\
Overall response rate by molecular subtypes & \\
$\quad$ Luminal & $67.4 \%$ & $60.9 \%$ \\
Her-2-positive & $75.0 \%$ & $87.5 \%$ \\
Triple negative & $68.8 \%$ & $87.5 \%$ \\
Median progression-free & 9.8 months & 9.3 months \\
survival & & \\
First-line & 11.7 months & 11.7 months \\
Second-line & 7.7 months & 6.6 months \\
Third- or more lines & 7.6 months & 7.6 months \\
\hline
\end{tabular}

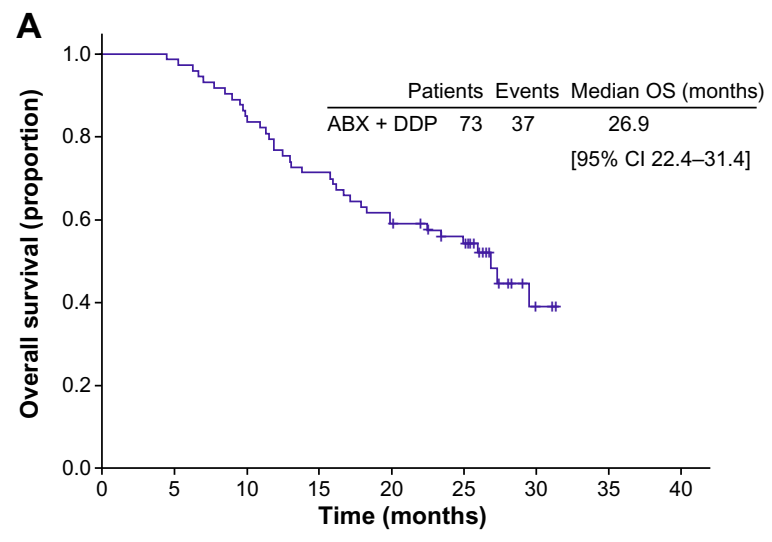

$\begin{array}{lllllllll}\text { No at risk } & 73 & 72 & 62 & 52 & 43 & 35 & 3 & 0\end{array}$

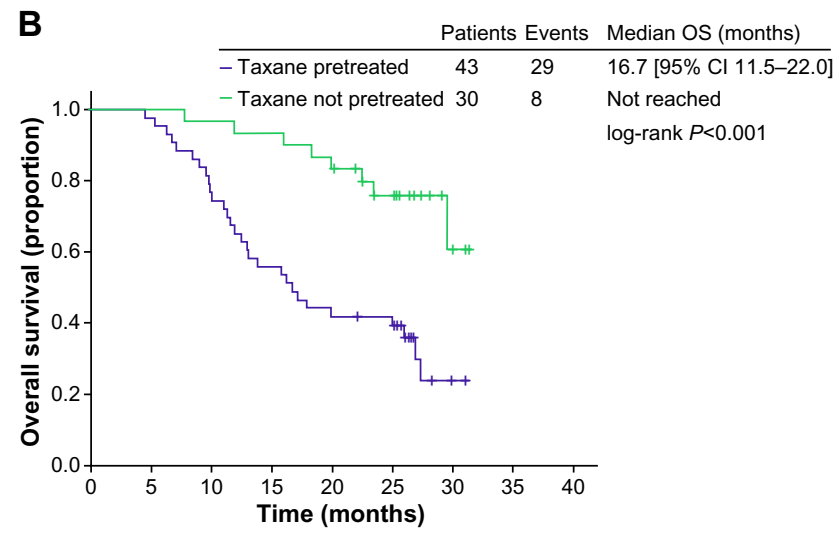

Figure I Kaplan-Meier curves for overall survival (A) and analysis of overall survival stratified by taxane pretreatment (B), assessed by investigators. Abbreviations: OS, overall survival; $\mathrm{Cl}$, confidence interval.

\section{Safety}

Treatment was well-tolerated and $63 \%$ of patients received nab-paclitaxel and cisplatin at the protocol-specified dose throughout the study. Overall, a total of 384 chemotherapy cycles were administered, with a median of 6 cycles. Delivered relative dose-intensity was $93.8 \%$ with nabpaclitaxel and $96.0 \%$ with cisplatin. Of the planned doses of nab-paclitaxel, 27 (37.0\%) and 16 (21.9\%) patients experienced dose reductions and interruptions, respectively. For cisplatin, 25 (34.2\%) and $5(6.8 \%)$ patients had dose reductions and interruptions, respectively. Neutropenia was the most common reason for dose adjustment.

A summary of AEs that occurred during and 1 month after treatment is presented by severity in Table 4 . The most common and severe treatment-related hematologic AEs were grade 3/4 neutropenia and leukopenia, which occurred in $62(84.9 \%)$ and 54 (75.3\%) patients, respectively. Grade 4 neutropenia occurred in 46 patients $(63.0 \%)$, whereas febrile neutropenia occurred in 9 patients $(12.3 \%)$. There were 27 patients (37.0\%) who received dose reductions because of hematologic toxicity, among whom 5 patients $(6.8 \%)$ experienced dose adjustment twice.

Grade 3 peripheral neuropathy was an accumulated doselimiting toxicity occurring in 19 patients $(26.0 \%)$, among whom 13 had to stop chemotherapy as a result of no recovery to grade 2 or less, even with an allowance of 2 weeks' delay as per protocol. However, all patients recovered to grade 2 or less neurotoxicity within 3 months after treatment stopped, whereas only one patient still experienced grade 2 sensory neurotoxicity 1 year after the last dose.

Skin rash was reported by Tang et al in BMC cancer. ${ }^{20}$ It is another common toxicity mainly caused by nabpaclitaxel and present in 27 patients $(37.0 \%)$. The most common sites involved were face (14/27), neck (14/27), limbs (18/27), and frictional parts of the trunk (10/27). Macular and papular rash with pruritus commonly occurred 2 (range, 1-7) days after the first day of chemotherapy. Only one patient developed grade 3 skin toxicity with generalized erythroderma and disfigurement of the face requiring dose reduction. The rash gradually regressed 2 (range, 1-10) days after using antihistamines, and pigmentation remained in $13 / 27$ cases. The incidence rate of skin rash was significantly different between Chinese and Western patients. ${ }^{21}$

Other common toxicities of all grades included alopecia $(100 \%)$, nausea $(64.4 \%)$, vomiting $(61.6 \%)$, and fatigue (34.2\%). Most of these AEs were not severe and could be 
A

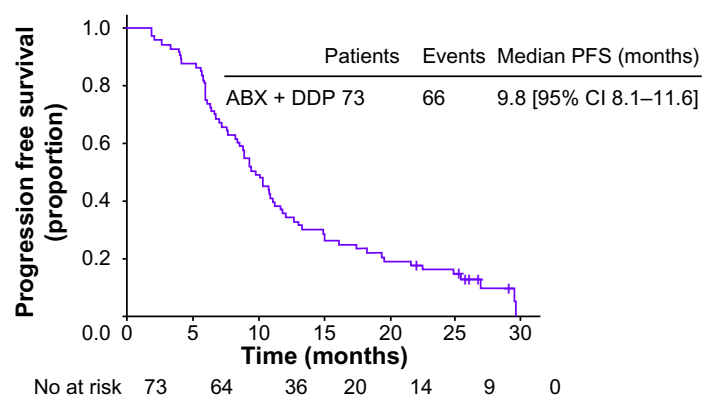

C

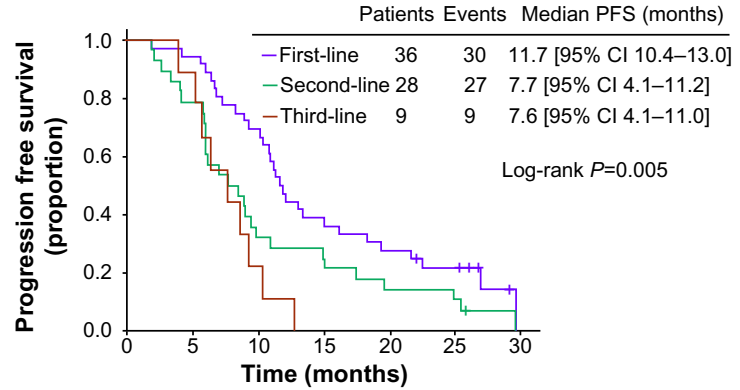

E

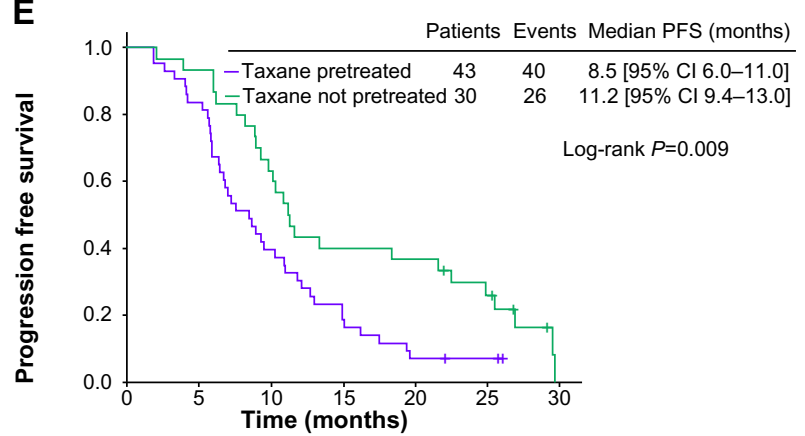

B

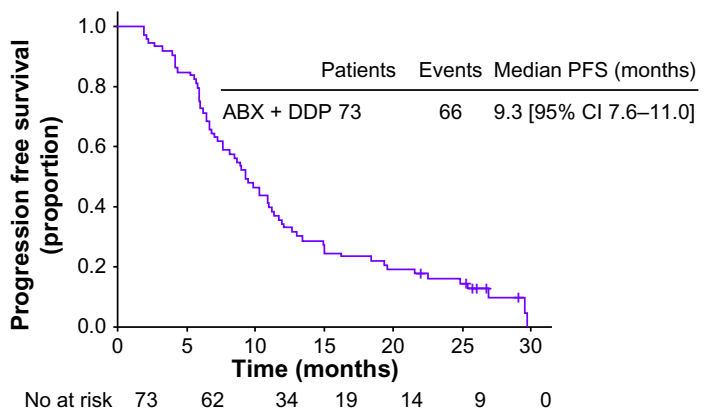

D
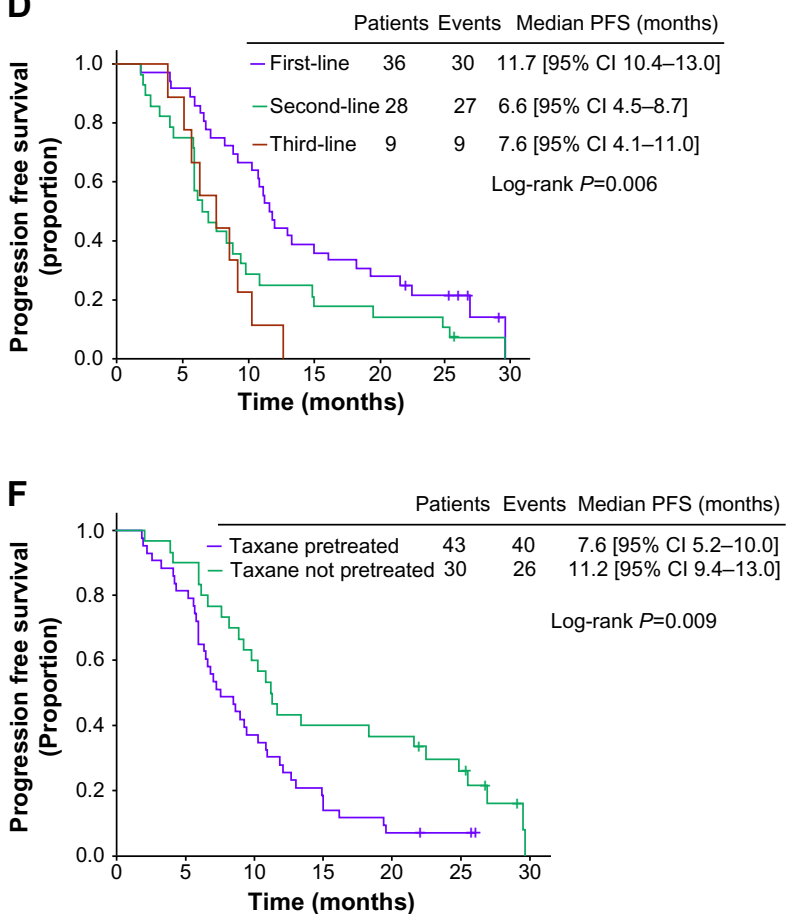

Figure 2 Kaplan-Meier curves for progression-free survival. For all patients, investigator assessment (A) and independent review (B). For patients stratified by lines of therapy, investigator assessment (C) and independent review (D). For patients stratified by taxane pretreatment, investigator assessment (E) and independent review (F). Abbreviations: $\mathrm{Cl}$, confidence interval; PFS, progression-free survival.

managed well. No hypersensitivity reactions were observed during the infusion of nab-paclitaxel.

\section{Discussion}

To our knowledge, this is the first prospective study to investigate the efficacy and toxicity of weekly nab-paclitaxel and cisplatin combination in breast cancer. The rationale for this novel regimen is based on single-agent activity and synergism of the two drugs. Weekly nab-paclitaxel has been regarded as the most effective monotherapy in breast cancer. ${ }^{14} \mathrm{~A}$ synergistic effect is present between taxanes and platinum salts (cisplatin and carboplatin) in human breast cancer and other solid tumors, motivating us to test the combination of the two drugs. ${ }^{22}$ Several trials adding other drugs to nab-paclitaxel have been conducted to further improve the efficacy, such as carboplatin, gemcitabine, bevacizumab, and herceptin. ${ }^{23-25}$ On the basis of our knowledge, this is also the first trial showing that the already-strong antitumor activity of weekly nab-paclitaxel for MBC can be further increased by adding a chemotherapeutic agent.

Our results demonstrated an investigator-assessed ORR of $67.1 \%$ in patients with $\mathrm{MBC}$, which was further validated by an independent radiology review and met its primary endpoint with $60 \%$ of ORR for the whole population. Taxanes, such as paclitaxel and docetaxel, are a cornerstone of treatment for MBC patients, especially considering the fact that many patients with recurrent disease already have had substantial anthracycline exposure in the neoadjuvant and/or adjuvant 
Table 4 Treatment-related toxicities by grade $(n=73)$

\begin{tabular}{|c|c|c|c|c|c|c|c|c|}
\hline \multirow[t]{2}{*}{ Toxicity } & \multicolumn{2}{|c|}{ Grade I } & \multicolumn{2}{|c|}{ Grade 2} & \multicolumn{2}{|c|}{ Grade 3} & \multicolumn{2}{|c|}{ Grade 4} \\
\hline & No & $\%$ & No & $\%$ & No & $\%$ & No & $\%$ \\
\hline \multicolumn{9}{|l|}{ Hematologic } \\
\hline Neutropenia & 1 & 1.4 & 9 & 12.3 & 16 & 21.9 & 46 & 63.0 \\
\hline Leukopenia & 2 & 2.7 & 15 & 20.5 & 39 & 53.4 & 16 & 21.9 \\
\hline Febrile neutropenia & & & & & 9 & 12.3 & 0 & 0 \\
\hline Thrombocytopenia & 6 & 8.2 & 9 & 12.3 & 1 & $\mathrm{I} .4$ & 0 & 0 \\
\hline Anemia & II & 15.1 & 44 & 60.3 & 10 & 13.7 & 3 & 4.1 \\
\hline \multicolumn{9}{|l|}{ Nonhematologic } \\
\hline Rash & 19 & 26.0 & 7 & 9.6 & I & 1.4 & 0 & 0 \\
\hline $\begin{array}{l}\text { Peripheral } \\
\text { neuropathy }\end{array}$ & 16 & 21.9 & 18 & 24.7 & 19 & 26.0 & 0 & 0 \\
\hline Alopecia & 31 & 42.5 & 42 & 57.5 & & & & \\
\hline Fatigue & 22 & 30.1 & 3 & 4.1 & 0 & 0 & 0 & 0 \\
\hline Nausea & 34 & 46.6 & 11 & 15.1 & 2 & 2.7 & 0 & 0 \\
\hline Vomiting & 31 & 42.5 & 12 & 16.4 & 2 & 2.7 & 0 & 0 \\
\hline Diarrhea & 2 & 2.7 & 5 & 6.8 & 2 & 2.7 & 0 & 0 \\
\hline Constipation & 10 & 13.7 & 2 & 2.7 & 0 & 0 & 0 & 0 \\
\hline Liver dysfunction & 6 & 8.2 & 0 & 0 & 0 & 0 & 0 & 0 \\
\hline Mucositis oral & 2 & 2.7 & 2 & 2.7 & I & 1.4 & 0 & 0 \\
\hline Abdominal pain & 8 & 11.0 & 2 & 2.7 & 0 & 0 & 0 & 0 \\
\hline Fever & 3 & 4.1 & 0 & 0 & 0 & 0 & 0 & 0 \\
\hline Anorexia & 22 & 30.1 & 2 & 2.7 & 0 & 0 & 0 & 0 \\
\hline $\begin{array}{l}\text { Hand-foot } \\
\text { syndrome }\end{array}$ & 1 & 1.4 & 2 & 2.7 & 0 & 0 & & \\
\hline $\begin{array}{l}\text { Myalgia and } \\
\text { arthralgia }\end{array}$ & 5 & 6.8 & 1 & 1.4 & 0 & 0 & 0 & 0 \\
\hline $\begin{array}{l}\text { Skin } \\
\text { hyperpigmentation }\end{array}$ & 9 & 12.3 & 5 & 6.8 & 0 & 0 & 0 & 0 \\
\hline Blurred vision & 2 & 2.7 & 2 & 2.7 & 0 & 0 & 0 & 0 \\
\hline Nail change & 5 & 6.8 & 3 & 4.1 & 0 & 0 & 0 & 0 \\
\hline Insomnia & 4 & 5.5 & 0 & 0 & 0 & 0 & 0 & 0 \\
\hline Hearing impaired & 0 & 0 & I & 1.4 & 0 & 0 & 0 & 0 \\
\hline Edema & 2 & 2.7 & 0 & 0 & 0 & 0 & 0 & 0 \\
\hline Dysphasia & I & 1.4 & 0 & 0 & 0 & 0 & 0 & 0 \\
\hline Watering eyes & I & 1.4 & 1 & 1.4 & 0 & 0 & 0 & 0 \\
\hline Dizziness & 2 & 2.7 & 0 & 0 & 0 & 0 & 0 & 0 \\
\hline Dyspnea & I & 1.4 & 0 & 0 & 0 & 0 & 0 & 0 \\
\hline
\end{tabular}

setting, and rechallenging anthracyclines is generally avoided. More important, this regimen provided a quick response. A large percentage of patients (83.7\%) experienced quick, remarkable tumor shrinkage with only two cycles of chemotherapy, which was quicker than the reported regimens, such as capecitabine/docetaxel, which showed a majority of all responses $(75.5 \%)$ occurring in the first four treatment cycles. ${ }^{26}$ Therefore, this doublet using a dose-dense new formulation of paclitaxel should be further explored to meet the unmet needs of MBC patients.

This new combination regimen had excellent efficacy in term of PFS and OS, as well as ORR, when compared with other taxane-based regimens (even the combination of taxane and molecular targeting agents in patients with $\mathrm{MBC}$; Table 5). ${ }^{26-31}$ In the 36 patients who received the chemotherapy as the first-line treatment, ORR was as high as $80.6 \%$. In MBC patients receiving chemotherapy only, longer PFS and OS with this doublet were noted when compared with capecitabine/ docetaxel ${ }^{26}$ or gemcitabine/paclitaxel. ${ }^{27}$ This regimen should be therefore compared with standard strategies for the treatment of MBC. It should also be explored in the neoadjuvant setting because higher and quicker objective responses are more desired there. Even as second- and third-line or more treatments, this regimen still had substantial antitumor activity, with ORRs of $57.1 \%$ and $44.4 \%$, respectively, which is higher than reported in the literature..$^{32}$ Therefore, our data present a strong rationale for its use throughout the disease course.

An analysis of our data showed that this doublet is effective in patients pretreated with taxanes. As reported by Guo et al, rechallenging taxane as first- and later-line treatment for patients with recurrent disease after (neo-)adjuvant taxanebased therapy yielded response rates of $48.6 \%$ and $28.2 \%$, respectively, which was considered by the authors as a reasonable option. ${ }^{33}$ In our study, more than half of the patients (58.9\%) had been pretreated with taxanes, among whom 12 patients (16.4\%) were exposed to taxanes in the metastatic setting. The subgroup analysis of our data showed $58.1 \%$ of ORRs in taxane-exposed patients, which further validates the strong antitumor activities of this novel regimen.

It is always an interesting topic whether efficacy of chemotherapeutic agent is related to any specific molecular subtype of breast cancer. A recent meta-analysis from Early Breast Cancer Trialists' Collaborative Group showed that both anthracycline and taxane can provide benefit in patients with early breast cancer, regardless of estrogen receptor status, indicating that chemotherapy benefit is not limited to any specific molecular subtype of breast cancer. ${ }^{34}$ Our results showed there was no significant association of ORR or PFS with luminal type or HER2-positive or triple-negative breast cancer, indicating that the doublet might be equally effective across these molecular subtypes.

As a novel generation compound, nab-paclitaxel in combination with cisplatin has been shown to improve efficacy, and it is natural to question whether there will be additive toxicity. The most frequently reported grade $3 / 4$ AEs of weekly nab-paclitaxel $\left(150 \mathrm{mg} / \mathrm{m}^{2}\right)$ alone included neutropenia (44\%) and sensory neuropathy $(14 \%) \cdot{ }^{14}$ In our study, the combination increased the grade $3 / 4$ neutropenia and neurotoxicity to $84.9 \%$ and $26 \%$, respectively. However, neutropenia was clinically manageable with the use of granulocyte colony-stimulating factors and dose-adjustment. Neurotoxicity is another concern of the combined regimen. In our study, all grades of peripheral neurotoxicity occurred 
Table 5 Taxane-containing regimens for metastatic breast cancer

\begin{tabular}{|c|c|c|c|c|c|c|}
\hline Study & Regimen & $\begin{array}{l}\text { Study design } \\
\text { and setting }\end{array}$ & $\begin{array}{l}\text { Number } \\
\text { of patients }\end{array}$ & $\begin{array}{l}\text { Overall } \\
\text { response } \\
\text { rate }\end{array}$ & $\begin{array}{l}\text { Median time to } \\
\text { progression/progression- } \\
\text { free survival (months) }\end{array}$ & $\begin{array}{l}\text { Median overall } \\
\text { survival } \\
\text { (months) }\end{array}$ \\
\hline Our study & $\begin{array}{l}\text { Nab-paclitaxel } 125 \mathrm{mg} / \mathrm{m}^{2} \text {, days I, } \\
8, \mathrm{I} 5 \text { + DDP } 75 \mathrm{mg} / \mathrm{m}^{2}, \mathrm{q} 4 \mathrm{w}\end{array}$ & $\begin{array}{l}\text { Phase II, } \\
\text { all lines }\end{array}$ & 73 & $67.1 \%$ & 9.8 & 26.9 \\
\hline Our study & Investigator assessment & First-line & 36 & $80.6 \%$ & 11.7 & NR \\
\hline (first-line) & Independent assessment & First-line & 36 & $77.8 \%$ & 11.7 & \\
\hline $\begin{array}{l}\text { O'Shaughnessy } \\
\text { et } \mathrm{al}^{26}\end{array}$ & $\begin{array}{l}\text { Capecitabine } 1,250 \mathrm{mg} / \mathrm{m}^{2} \\
\text { twice daily on days I to I4 } \\
\text { + docetaxel } 75 \mathrm{mg} / \mathrm{m}^{2} \text { day I, q3w }\end{array}$ & $\begin{array}{l}\text { Phase III, } \\
\text { all lines }\end{array}$ & 255 & $42 \%$ & 6.1 & 14.5 \\
\hline Albain et $\mathrm{a}^{27}$ & $\begin{array}{l}\text { Gemcitabine } 1,250 \mathrm{mg} / \mathrm{m}^{2} \text { days I, } \\
8 \text { + paclitaxel } 175 \mathrm{mg} / \mathrm{m}^{2} \text { day I, } \mathrm{q} 3 \mathrm{w}\end{array}$ & $\begin{array}{l}\text { Phase III, } \\
\text { first-line }\end{array}$ & 266 & $41.4 \%$ & 6.1 & 18.6 \\
\hline Miller et $\mathrm{a}^{28}$ & $\begin{array}{l}\text { Paclitaxel } 90 \mathrm{mg} / \mathrm{m}^{2} \text { days } \mathrm{I}, 8 \\
\mathrm{I} 5+\text { bevacizumab } 10 \mathrm{mg} / \mathrm{kg} \\
\text { days I and } \mathrm{I}, \mathrm{q} 4 \mathrm{w}\end{array}$ & $\begin{array}{l}\text { Phase III, } \\
\text { first-line }\end{array}$ & 347 & $36.9 \%$ & 11.8 & 26.7 \\
\hline Miles et $\mathrm{al}^{29}$ & $\begin{array}{l}\text { Docetaxel } 100 \mathrm{mg} / \mathrm{m}^{2}+ \\
\text { bevacizumab } 15 \mathrm{mg} / \mathrm{kg} \text { day I, q3w }\end{array}$ & $\begin{array}{l}\text { Phase III, } \\
\text { first-line }\end{array}$ & 247 & $63 \%$ & 10.1 & 30.3 \\
\hline Slamon et $\mathrm{al}^{30}$ & Chemotherapy plus heceptin & $\begin{array}{l}\text { Phase III, } \\
\text { first-line }\end{array}$ & 235 & $50 \%$ & 7.4 & 25.1 \\
\hline Wardley et $\mathrm{a}^{31}$ & $\begin{array}{l}\text { Heceptin }(8 \mathrm{mg} / \mathrm{kg} \text { loading; } 6 \mathrm{mg} / \mathrm{kg} \\
\mathrm{q} 3 \mathrm{w})+ \text { docetaxel }\left(75 \mathrm{mg} / \mathrm{m}^{2} \mathrm{q} 3 \mathrm{w}\right) \\
+ \text { xeloda }\left(950 \mathrm{mg} / \mathrm{m}^{2} \text { twice daily }\right. \\
\text { on days I to } 14 \mathrm{q} 3 \mathrm{w})\end{array}$ & $\begin{array}{l}\text { Phase II, } \\
\text { first-line }\end{array}$ & 113 & $70.5 \%$ & 18.6 & NR \\
\hline
\end{tabular}

Abbreviations: $q 3 w$, every 3 weeks; $q 4 w$, every 4 weeks; NR, not reached.

in 53 patients $(72.6 \%)$, with 19 patients $(26.0 \%)$ at grade 3 . Among them, 13 patients with grade 3 peripheral neurotoxicity who showed no recovery to grade 2 or less had to stop chemotherapy, as our protocol allowed delay of chemotherapy for no more than 2 weeks. Gradishar et al reported that the median recovery time to grade 2 or less for nab-paclitaxelinduced neurotoxicity was about 22 days. ${ }^{8}$ Further follow-up of our patients showed that most of the neuropathy was sensory neuropathy, and all patients could recover to grade 2 or less within 3 months after the last dose, whereas only a single patient still experienced grade 2 toxicity 1 year after. Therefore, further assessment of neurotoxicity of this doublet should be also done in the future Phase III trial.

This trial should be also interpreted within the context of trials of weekly nab-paclitaxel-based therapy in MBC patients. ${ }^{24,35,36}$ It remains a question whether we can improve efficacy of weekly nab-paclitaxel by combining other antitumor agents. The combination with trastuzumab proves to be a reasonable option, with ORRs and median PFS ranging from $52.4 \%$ to $62.5 \%$, and from 16.6 to 18.7 months, respectively. ${ }^{24,36}$ Weekly use of nab-paclitaxel/bevacizumab was promising in a Phase II trial; ${ }^{35}$ however, a subsequent large Phase III trial reported by Rugo et al did not show any more benefits than a weekly paclitaxel/bevacizumab doublet. ${ }^{37}$ In combination with other chemotherapeutic agents, a weekly nab-paclitaxel-based combination has never been reported to be successful in $\mathrm{MBC}$ to our knowledge. A recent Phase III trial demonstrated that weekly use of the doublet of nab-paclitaxel/carboplatin is promising in non-small-cell lung cancer patients. ${ }^{38}$ Our study first demonstrates that in the management of MBC patients, the efficacy of weekly nab-paclitaxel can be improved by adding cisplatin.

\section{Conclusion}

The results of this trial add to the clinical evidence that the combination of weekly nab-paclitaxel and cisplatin has high efficacy, quick response, and manageable toxicity in MBC. This doublet might be equally effective against luminal breast cancer as well as HER2-positive and triple-negative breast cancer. A further Phase III trial is warranted.

\section{Acknowledgments}

We are grateful to the patients who participated in this trial. Partial support for the study was obtained from Celgene.

\section{Disclosure}

The authors report no conflicts of interest in this work.

\section{References}

1. Parkin DM, Bray F, Ferlay J, Pisani P. Global cancer statistics, 2002. CA Cancer J Clin. 2005;55(2):74-108.

2. DeVita VT, Hellman JS, Rosenberg JS. Cancer Principles and Practice of Oncology. 7th ed. Philadelphia: Lippincott Williams \& Wilkins; 2005. 
3. Kamby C, Vejborg I, Kristensen B, Olsen LO, Mouridsen HT. Metastatic pattern in recurrent breast cancer. Special reference to intrathoracic recurrences. Cancer. 1988;62(10):2226-2233.

4. Rhee J, Han SW, Oh DY, et al. The clinicopathologic characteristics and prognostic significance of triple-negativity in node-negative breast cancer. BMC Cancer. 2008;8:307.

5. Ries LAG, Young JL, Keel GE, Eisner MP, Lin YD, Horner M-J. SEER Survival Monograph: Cancer Survival Among Adults: US SEER Program, 1988-2001, Patient and Tumor Characteristics. NIH Publication 07-6215. Bethesda, MD: National Cancer Institute; 2007.

6. Mayer EL, Burstein HJ. Chemotherapy for metastatic breast cancer. Hematol Oncol Clin North Am. 2007;21(2):257-272.

7. Gradishar WJ. Albumin-bound paclitaxel: a next-generation taxane. Expert Opin Pharmacother. 2006;7(8):1041-1053.

8. Gradishar WJ, Tjulandin S, Davidson N, et al. Phase III trial of nanoparticle albumin-bound paclitaxel compared with polyethylated castor oil-based paclitaxel in women with breast cancer. J Clin Oncol. 2005;23(31):7794-7803.

9. Henderson IC, Bhatia V. Nab-paclitaxel for breast cancer: a new formulation with an improved safety profile and greater efficacy. Expert Rev Anticancer Ther. 2007;7(7):919-943.

10. Pinder MC, Ibrahim NK. Nanoparticle albumin-bound paclitaxel for treatment of metastatic breast cancer. Drugs Today (Barc). 2006;42(9):599-604.

11. Desai N, Trieu V, Yao Z, et al. Increased antitumor activity, intratumor paclitaxel concentrations, and endothelial cell transport of cremophorfree, albumin-bound paclitaxel, ABI-007, compared with cremophorbased paclitaxel. Clin Cancer Res. 2006;12(4):1317-1324.

12. Nyman DW, Campbell KJ, Hersh E, et al. Phase I and pharmacokinetics trial of ABI-007, a novel nanoparticle formulation of paclitaxel in patients with advanced nonhematologic malignancies. $J$ Clin Oncol. 2005;23(31):7785-7793

13. Blum JL, Savin MA, Edelman G, et al. Phase II study of weekly albuminbound paclitaxel for patients with metastatic breast cancer heavily pretreated with taxanes. Clin Breast Cancer. 2007;7(11):850-856.

14. Gradishar WJ, Krasnojon D, Cheporov S, et al. Significantly longer progression-free survival with nab-paclitaxel compared with docetaxel as first-line therapy for metastatic breast cancer. $J$ Clin Oncol. 2009;27(22):3611-3619.

15. Eisenhauer EA, Therasse P, Bogaerts J, et al. New response evaluation criteria in solid tumours: revised RECIST guideline (version 1.1). Eur J Cancer. 2009;45(2):228-247.

16. Oken MM, Creech RH, Tormey DC, et al. Toxicity and response criteria of the Eastern Cooperative Oncology Group. Am J Clin Oncol. 1982;5(6):649-655.

17. ClinicalTrials.org [homepage on the Internet]. A Combination of Abraxane and Cisplatin in Metastatic Breast Cancer. Available from: http://clinicaltrials.gov/show/NCT01149798.

18. Common Terminology Criteria for Adverse Events (CTCAE) Version 4.0 Published May 28, 2009; Revised version 4.03 June 14, 2010. National Cancer Institute, National Institutes of Health, US Department of Health and Human Services. (Vol. Available from: http://evs.nci.nih. gov/ftp1/ CTCAE/CTCAE_4.03_2010-06-14_QuickReference_5x7.pdf).

19. Simon R. Optimal two-stage designs for phase II clinical trials. Control Clin Trials. 1989;10(1):1-10.

20. Tang LC, Wang BY, Sun S, et al. Higher rate of skin rash in a phase II trial with weekly nanoparticle albumin-bound paclitaxel and cisplatin combination in Chinese breast cancer patients. BMC Cancer. 2013;13(1):232.

21. Yamamoto Y, Kawano I, Iwase H. Nab-paclitaxel for the treatment of breast cancer: efficacy, safety, and approval. Onco Targets Ther. 2011;4:123-136.
22. Crown J, Pegram M. Platinum-taxane combinations in metastatic breast cancer: an evolving role in the era of molecularly targeted therapy. Breast Cancer Res Treat. 2003;79 Suppl 1:S11-S18.

23. Lobo C, Lopes G, Baez O, et al. Final results of a phase II study of nab-paclitaxel, bevacizumab, and gemcitabine as first-line therapy for patients with HER2-negative metastatic breast cancer. Breast Cancer Res Treat. 2010;123(2):427-435.

24. Conlin AK, Seidman AD, Bach A, et al. Phase II trial of weekly nanoparticle albumin-bound paclitaxel with carboplatin and trastuzumab as first-line therapy for women with HER2-overexpressing metastatic breast cancer. Clin Breast Cancer. 2010;10(4):281-287.

25. Roy V, LaPlant BR, Gross GG, Bane CL, Palmieri FM; North Central Cancer Treatment Group. Phase II trial of weekly nab (nanoparticle albumin-bound)-paclitaxel (nab-paclitaxel) (Abraxane) in combination with gemcitabine in patients with metastatic breast cancer (N0531). Ann Oncol. 2009;20(3):449-453.

26. O'Shaughnessy J, Miles D, Vukelja S, et al. Superior survival with capecitabine plus docetaxel combination therapy in anthracyclinepretreated patients with advanced breast cancer: phase III trial results. J Clin Oncol. 2002;20(12):2812-2823.

27. Albain KS, Nag SM, Calderillo-Ruiz G, et al. Gemcitabine plus Paclitaxel versus Paclitaxel monotherapy in patients with metastatic breast cancer and prior anthracycline treatment. J Clin Oncol. 2008;26(24):3950-3957.

28. Miller K, Wang M, Gralow J, et al. Paclitaxel plus bevacizumab versus paclitaxel alone for metastatic breast cancer. $N$ Engl $J$ Med. 2007;357(26):2666-2676.

29. Miles DW, Chan A, Dirix LY, et al. Phase III study of bevacizumab plus docetaxel compared with placebo plus docetaxel for the first-line treatment of human epidermal growth factor receptor 2-negative metastatic breast cancer. J Clin Oncol. 2010;28(20):3239-3247.

30. Slamon DJ, Leyland-Jones B, Shak S, et al. Use of chemotherapy plus a monoclonal antibody against HER 2 for metastatic breast cancer that overexpresses HER2. N Engl J Med. 2001;344(11):783-792.

31. Wardley AM, Pivot X, Morales-Vasquez F, et al. Randomized phase II trial of first-line trastuzumab plus docetaxel and capecitabine compared with trastuzumab plus docetaxel in HER2-positive metastatic breast cancer. J Clin Oncol. 2010;28(6):976-983.

32. Jones SE. Metastatic breast cancer: the treatment challenge. Clin Breast Cancer. 2008;8(3):224-233.

33. Guo X, Loibl S, Untch M, et al. Re-challenging taxanes in recurrent breast cancer in patients treated with (neo-)adjuvant taxane-based therapy. Breast Care (Basel). 2011;6(4):279-283.

34. Palmieri C, Jones A. The 2011 EBCTCG polychemotherapy overview. Lancet. 2012;379(9814):390-392.

35. Danso MA, Blum JL, Robert NJ, et al. Phase II trial of weekly nabpaclitaxel in combination with bevacizumab as first-line treatment in metastatic breast cancer [abstract]. J Clin Oncol. 2008;26; (ASCO Annual Meeting Proceedings): Abstract 1075.

36. Mirtsching B, Cosgriff T, Harker G, Keaton M, Chidiac T, Min M. A phase II study of weekly nanoparticle albumin-bound paclitaxel with or without trastuzumab in metastatic breast cancer. Clin Breast Cancer. 2011;11(2):121-128.

37. Rugo HS, Barry WT, Moreno-Aspitia A, et al. CALGB 40502/NCCTG N063H: Randomized phase III trial of weekly paclitaxel (P) compared to weekly nanoparticle albumin bound nab-paclitaxel (NP) or ixabepilone (Ix) with or without bevacizumab (B) as first-line therapy for locally recurrent or metastatic breast cancer (MBC) [abstract]. J Clin Oncol. 2012;30:CRA1002.

38. Socinski MA, Langer CJ, Okamoto I, et al. Safety and efficacy of weekly $n \mathrm{~b}^{\circledR}$-paclitaxel in combination with carboplatin as first-line therapy in elderly patients with advanced non-small-cell lung cancer. Ann Oncol. 2013;24(2):314-321. 


\section{Publish your work in this journal}

The International Journal of Nanomedicine is an international, peerreviewed journal focusing on the application of nanotechnology in diagnostics, therapeutics, and drug delivery systems throughout the biomedical field. This journal is indexed on PubMed Central, MedLine, CAS, SciSearch $\AA$, Current Contents ${ }^{\circledR} /$ Clinical Medicine,

Journal Citation Reports/Science Edition, EMBase, Scopus and the Elsevier Bibliographic databases. The manuscript management system is completely online and includes a very quick and fair peer-review system, which is all easy to use. Visit http://www.dovepress.com/ testimonials.php to read real quotes from published authors.

Submit your manuscript here: http://www.dovepress.com/international-journal-of-nanomedicine-journal 